\title{
Future Trends of the Pneumatic Process
}

by J. E. Stukel

$I^{T}$ $T$ is a recognized fact that the bessemer process has been diminishing in importance in the U. S., and there was every reason to believe that this decline would continue. However, two recent European developments in the pneumatic process have altered this picture. The aim of both of these is to keep the nitrogen content of the resulting steel at or lower than open hearth values $(0.004$ pct $N)$. These low nitrogen values are achieved by using oxygen rather than air, and the primary difference between the two techniques is the manner in which the oxygen is introduced into the metal bath.

In the L-D (Austrian, oxygen lance) process, the bottom is sealed off, and oxygen is introduced to the metal by means of a vertically suspended, water cooled lance. At the oxygen-metal reaction zone the temperature exceeds $4000^{\circ} \mathrm{F}$, and the nitrogen pickup is rapid; therefore, oxygen 99.5 pct pure must be used to maintain a low nitrogen in the bath. Furthermore, this high reaction temperature volatilizes some iron and manganese (30 lb per ton of ingot), and the fumes are extremely voluminous. In order to avoid excessive air pollution expensive gas cleaning equipment is necessary.

In the OV process, a conventional type converter is used, blowing with a mixture of oxygen and steam. A higher oxygen concentration in the blast allows a greater scrap consumption; however, this must be balanced against a higher refractory consumption. Generally, a mixture of equal parts of oxygen and steam, having the same thermogenic power as air, achieves optimum results. In basiclined converters, the steam must be superheated to prevent condensation in the tuyeres which greatly reduces refractory life. Condensation does not appear to affect the acid bottom life. Since the temperature at the point of contact between the molten metal and the oxygen-steam blast is about the same as for an air blow, there is no additional fume formation. Furthermore, there is no slopping; the flame is sharp; and the end point is more definite than with ordinary air. At the temperature of gas-liquid contact, less nitrogen is absorbed than in the L-D process; so, the oxygen does not have to be as pure. In addition, a part of the steam dissociates so that about 15 pct less oxygen is required than in the top blowing method.

Normally, in Europe the L-D method is used on pig irons approaching the American pig iron analysis, while the basic OV technique is used to refine pig irons with 1.5 pct to 1.8 pct phosphorus. Recently, Kosmider ${ }^{1}$ has shown that the basic OV process can also be used on American type pig irons without the so-called after-blow.

Fig. 1 gives the operating cycle for both processes when using 45 -ton converters. The L-D process uses about 25 pct scrap, while the OV process without an afterblow uses about 5 pct scrap. From the figure it

J. E. STUKEL is with the Youngstown Sheet \& Tube Co., Youngstown, Ohio. can be seen that, the major factor allowing the greater production rates in the OV process is the shorter time of the blow. This is due, in the main, to the greater rate of delivery of the blast.

In order to get effective phosphorus removal, the lime: silica ratio of $3: 1$ should be used for both processes. According to Kosmider, ${ }^{1}$ the OV process gives the same degree of dephosphorization as the L-D method, but this is open to question since all the burnt lime may not be in solution by the end of the blow, and in the OV process there is less scrap to dilute the phosphorus. In any event, neither process will consistently produce a steel containing less than 0.01 pct $P$, using a single slag, when being charged with a 0.300 pet $P$ pig iron.

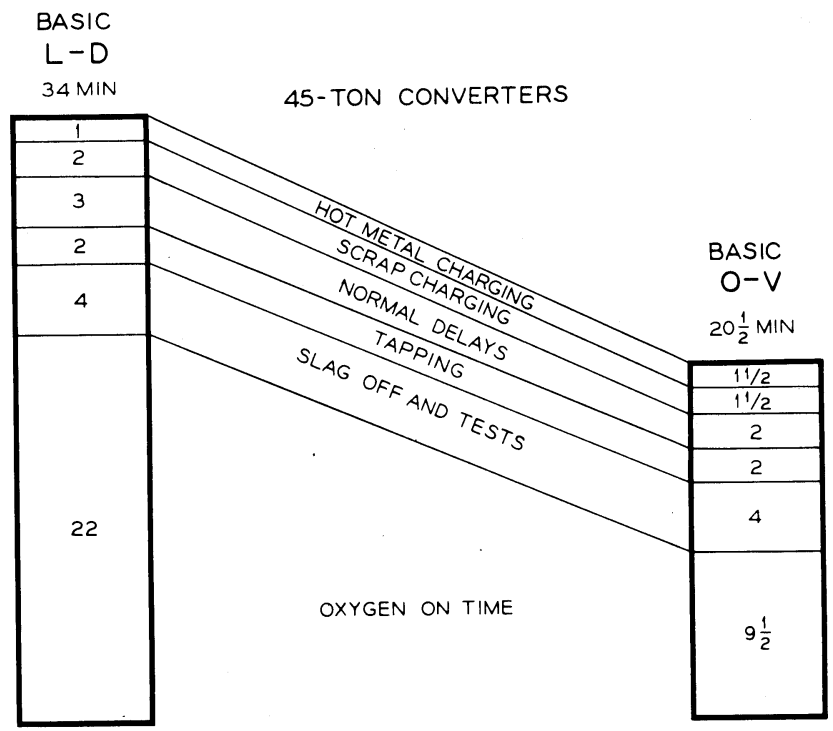

Fig. 1-Operating cycle for the L-D and $O V$ pneumatic processes.

In both processes, the blow is continued until the flame drops. Thus, only low carbon steels are made (0.03-0.04 pct C). Some recarburization has been successfully carried out in the ladle at Dofasco, where rimmed and killed grades up to 0.2 pct $\mathrm{C}$ are made. In Europe recarburization to $0.6 \mathrm{pct} C$ is accomplished by adding pig iron. It may be possible to meter the oxygen so that the blow can be stopped at the desired carbon level, provided phosphorus does not cause trouble. This may be easier to do in the L-D process than the OV process.

In conclusion, it can be said that plant location and local conditions will determine which of these pneumatic methods can be used to best advantage. It must be borne in mind that both of these techniques are relatively new and further research may make them even more effective to produce quality steel at a low cost. ${ }^{1} \mathrm{H}$. Kosmider, H. Neuhaus, and A. Weyer: Verblasen von Stahl-

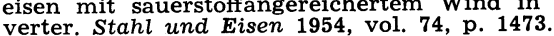

